\title{
Full mouth rehabilitation with extremely worn dentition
}

\author{
Hwa-Ryun Cha, Kyeong-Yeon Yeom, Yong-Sang Lee, Na-Hong Kim* \\ Department of Prosthodontic Dentistry, Veterans Health Service Medical Center, Seoul, Republic of Korea
}

Pathologic attrition leads to pathologic damage on occlusal plane, functional disorders, occlusal disharmony, esthetic problems, pulpal lesion, temporomandibular joint (TMJ) disorder. In this case, treatment plan should be considered for possibility of vertical dimension loss, occlusal pattern, esthetics, phonetics, amount of vertical dimension increase. This case report was a 71-year-old man who had severely worn dentition. Full mouth rehabilitation was carried out with vertical dimension increase due to limited space for prosthesis. After evaluation of provisional restorations for patient's compliance, final restorations were fabricated and routine clinical assessments were made. This case presents that a satisfactory clinical result was achieved by restoring the worn dentition. (J Dent Rehabil Appl Sci 2017;33(3):238-44)

Key words: tooth wear; vertical dimension; full mouth rehabilitation

\begin{abstract}
서론
치아 마모는 일생에 걸친 생리적인 현상이다. 생리적 치아 마모의 경우 치아와 치조골의 보상성 메커니즘이 존재하는 반면, 병적 치아 마모의 경우 보상성 기전보다 마모의 진행속도가 더 빠르기 때문에 교합면의 병리적 손상, 기능장애, 교합 이상, 심미문제, 치수병변, 턱관절 장애 등의 증상을 보일 수 있다. ${ }^{1}$ 병적 치아 마모를 갖는 환자에서는 원인을 분석하고 발치 전 기록, 전치부 치아 길이 측정, 발음, 안모평가, ${ }^{2}$ 상하악 치아의 조화, 기존 치 아의 고경, 교합면간 거리(interocclusal distance)를 ${ }^{3,4}$ 통 해 수직고경 상실 여부를 평가하고, 교합 양상, 심미, 발 음, 가능한 수직고경 증가량을 고려하여 치료 계획을 세 워야 한다. Turner ${ }^{5}$ 는 마모된 치아를 갖는 환자를 1. 과 도한 치아 마모와 함께 수직 교합고경 상실이 동반된 경 우 2. 과도한 치아 마모가 있으나 수직고경 상실은 없으 며 수복을 위한 악간 공간이 존재하는 경우 3. 과도한 치

\footnotetext{
${ }^{*}$ Correspondence to: Na-Hong Kim

Department of Prosthodontic Dentistry, Veterans Health Service Medical Center,

53, Jinhwangdo-ro 61gil, Gangdong-gu, Seoul, 05368, Republic of Korea

Tel: +82-2-2225-3976, Fax: +82-2-2225-3929, E-mail: tchaski@daum.net

Received: July 21, 2017/Last Revision: August 16, 2017/Accepted: August 21,

2017
}

아 마모가 있으나 수직 교합 고경의 상실은 없으며 수복 을 위한 악간 공간이 부족한 경우로 분류하였다.

본 증례의 환자는 수직고경 상실은 없으나 보철물을 위한 악간 공간이 부족한 'Turner classification 3'에 해당 하는 환자로 마모된 치아의 심미적인 개선과 상실치아의 수복을 주소로 내원하였다. 이에 수직고경 증가를 동반 한 전악 금속 도재관 수복을 하였고 기능적, 심미적으로 만족할 만한 결과를 얻었기에 보고하는 바이다.

\section{증례보고}

본 증례의 환자는 71세 남환으로 상악 우측 고정성 보 철물이 파절되어 재제작을 주소로 내원하였으며, 마모된 자연치아의 심미적인 개선도 원하였다(Fig. 1). 전신질환 으로는 고혈압과 협심증, 당뇨로 투약 중이었다. 턱관절 장애 및 비기능적인 구강악습관은 없었지만 질기고 딱딱 한 음식을 즐겨먹는다고 진술하였다. 임상검사 및 방사 


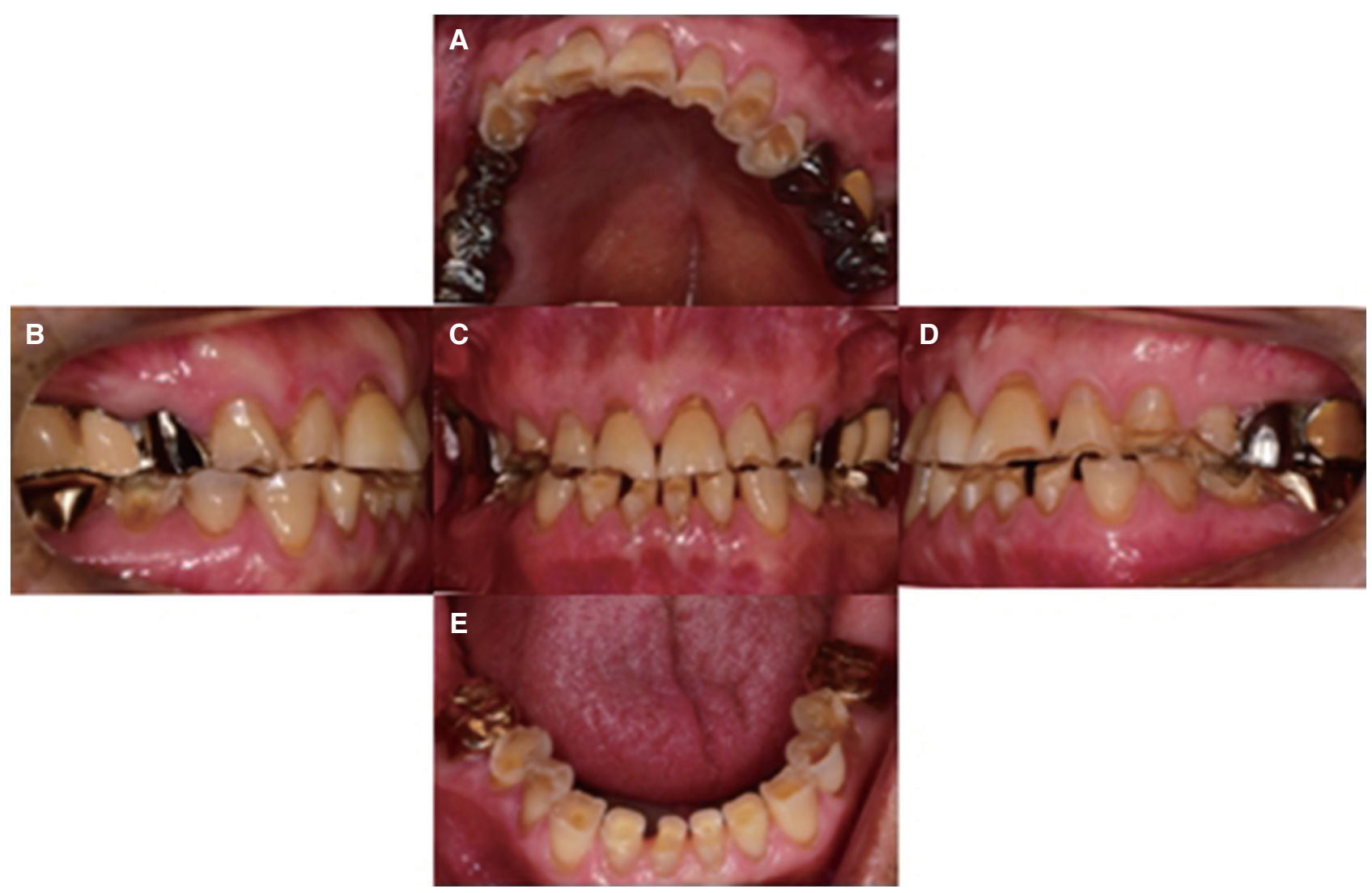

Fig. 1. Intraoral photograph before treatment. (A) Upper view, (B) Right view, (C) Frontal view, (D) Left view, (E) Lower view.

선 검사(Fig. 2)결과 특이할 만한 치주적 이상 소견은 없 었다.

전반적인 치아 교모가 교합 및 절단 $1 / 3$ 이상을 넘어서 진행된 상태였고 기존 보철물과 자연치의 교모 차이로 인해 교합 평면의 부조화와 절단교합을 보이고 있었다. \#15, 16, 37, 47번 치아는 상실되었고, \#15, 16번 상실 부 위는 \#14번과 17번을 지대치로 하는 4본 고정성 가공의 치로 수복되어 있었으며, \#17번은 정출되어 있었다. 4본 고정성 가공의치는 금속 도재관으로 수복되어 있었고, \#14번 치아의 도재파절 및 \#17번 금속 교합면의 천공이 발생한 상태였다.

먼저 환자의 수직고경 상실여부를 평가하기 위해 다 양한 검사들을 시행하였다. 교합면간 거리(interocclusal distance)는 $3 \mathrm{~mm}$ 로 평균치인 2 - $4 \mathrm{~mm}$ 범위 안에 있었 고, ${ }^{6}$ 순측 전정에서 전치 절단연까지의 길이는 상악 18 $\mathrm{mm}$, 하악 $17 \mathrm{~mm}$ 로 한국인의 평균인 상악 $20.8 \mathrm{~mm}$, 하 악 $17.3 \mathrm{~mm}$ 와 비교 했을 때 상악에서 평균치보다 약간 작았으며 상하악 순측 전정 사이 거리도 $33 \mathrm{~mm}$ 로 평균 치 $35 \mathrm{~mm}$ 와 큰 차이를 보이지 않았다.

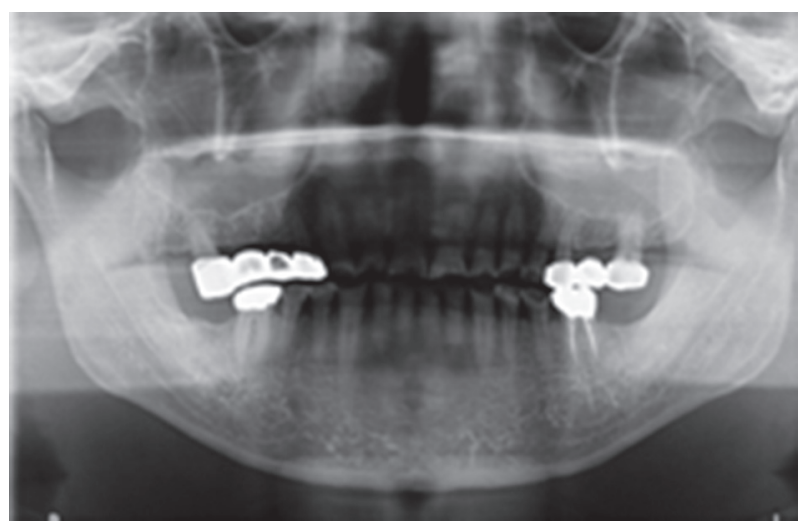

Fig. 2. Panoramic radiograph before treatment.

안모 검사 상, 수직고경 감소 시 나타나는 입술의 얇아 짐, 구각부의 처짐 등의 양상은 뚜렷이 관찰되지 않았다. $\mathrm{Willis}^{8}$ 계측법으로 평가하였을 때 동공간선에서 구각부 까지의 거리가 콧날개 아래(alar)에서 하악 하부까지 거 리와 유의할만한 차이가 없었다.

일련의 구내, 구외 검사 결과를 고려할 때, 수직고경의 상실은 없는 것으로 판단했다. 
진단을 위해 예비 인상을 채득하였고, Camper's 평면 과 좌우 동공간선을 참고하여 안궁 이전하고 양손 조작 술(bimanual manipulation)을 이용하여 중심위로 악간 관계를 채득하였다. 이후, 반조절성 교합기(Artex, Girrbach, Pforzheim, Germany)에 진단모형을 마운팅 하였 다.

마운팅한 진단모형을 분석한 결과 수직고경의 상실은 없지만 보철 수복을 위한 공간이 부족한 것으로 판단하 였다. 이에 교합기의 전방 유도핀(anterior guide pin)을 기준으로 $3.5 \mathrm{~mm}$ 의 수직고경 거상을 결정하였다. 심하 게 마모된 하악 전치는 하순과의 관계를 고려하여 치관 길이를 $8 \mathrm{~mm}$ 로 복원시켰고 교합평면의 높이는 구후 융 기의 $1 / 2$ 로 설정했으며 견치 유도 교합양식을 부여하였 다(Fig. 3). \#15, 16번 치아 부위는 임플란트 고정성 보철 물로 수복하기로 하였다.

퍼티(Express ${ }^{\mathrm{TM}}$ STD putty, 3M ESPE, USA)로 인덱 스를 제작하여 통법에 따라 상악과 하악의 모든 치아에 대한 임시수복을 하루에 시행하였다. 환자는 2 - 3주 마 다 내원하여 임시수복물에 대한 적응도를 평가하고 교합 조정을 하였다(Fig. 4).

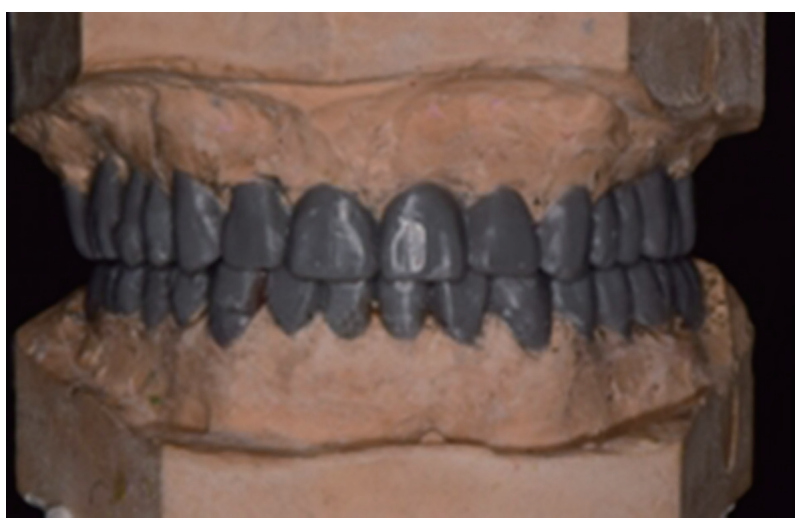

Fig. 3. Diagnostic waxup cast model.
\#15, 16번 치아 부위는 치조정 접근(crestal approach) 방식의 상악동 거상술로 상악동막 거상 후. 골이식을 포함하지 않고 임플란트(Osstem TS III SA, Osstem, Busan, Korea; \#15i: $4.5 \times 10$ mm, \#16i: $5.0 \times 8.5$ mm) 를 식립하였으며 초기고정이 양호하여 수술 당일 치유 지대주를 연결하였다.

3 개월간 임시 수복물을 사용하였고 관찰기간 동안 환 자의 불편감 및 이상소견은 관찰되지 않았다. 이에 임시 수복물의 수직고경과 견치 유도각 및 견치유도 교합을 이용하여 최종 보철물을 제작하기로 하였다.

최종 치아 삭제 후, 개인 트레이를 이용하여 고무 인상 재로(Imprint II Garant. Light Body, 3M ESPE, USA) 정밀 인상을 채득하여 주모형과 다이를 제작하였다(Fig. $5)$.

적응된 임시 수복물의 전방유도 및 교합 고경을 최종 수복물에 재현하기 위하여 임시 보철물의 모형과 작업 모형을 크로스 마운팅 하였고 전방유도판(Pattern resin, GC Corporation, Tokyo, Japan)을 제작하였다.

임플란트를 포함한 모든 보철물은 금속 도재관으로 제작되었으며 납형형성 후, 되깎이(cut-back)하고 주조하 여 코핑을 제작하였다(Fig. 6).

최종수복물 완성 전, 코핑을 시적하여 임시 수복물에서 설정한 악간관계가 제대로 반영되었는지 확인하고 고무 교합인기재(O-Bite, DMG, Hamburg, Germany)로 악간 관계를 다시 기록하여 오차를 수정하였다.

최종수복물은 임시 접착하여 4주간 평가한 후 별다 른 이상 소견이 없음을 확인하고 RMGI 시멘트(Rely X Luting 2, 3M ESPE, USA)로 최종 접착하였다. 임플란 트 고정성 보철물은 레진 시멘트(Premier ${ }^{\circledR}$ Implant Cement $^{\mathrm{TM}}$, The Dental Advisor, Plymouth Meeting, USA) 로 접착하였다(Fig. 7, 8). 최종수복물 장착 후, 심미적으 로 향상된 치열 및 안모를 보였다(Fig. 9).

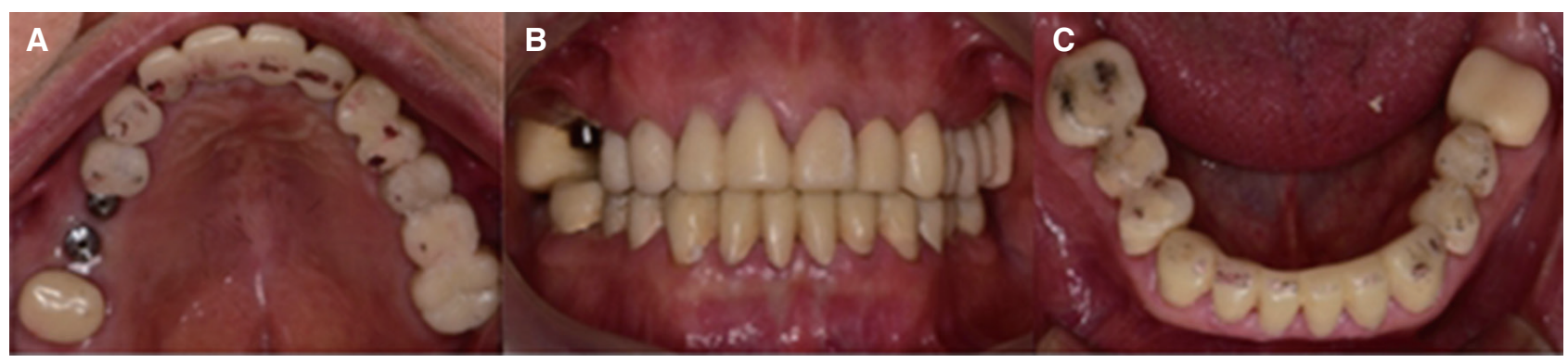

Fig. 4. Provisional restoration. (A) Upper view, (B) Frontal view, (C) Lower view. 

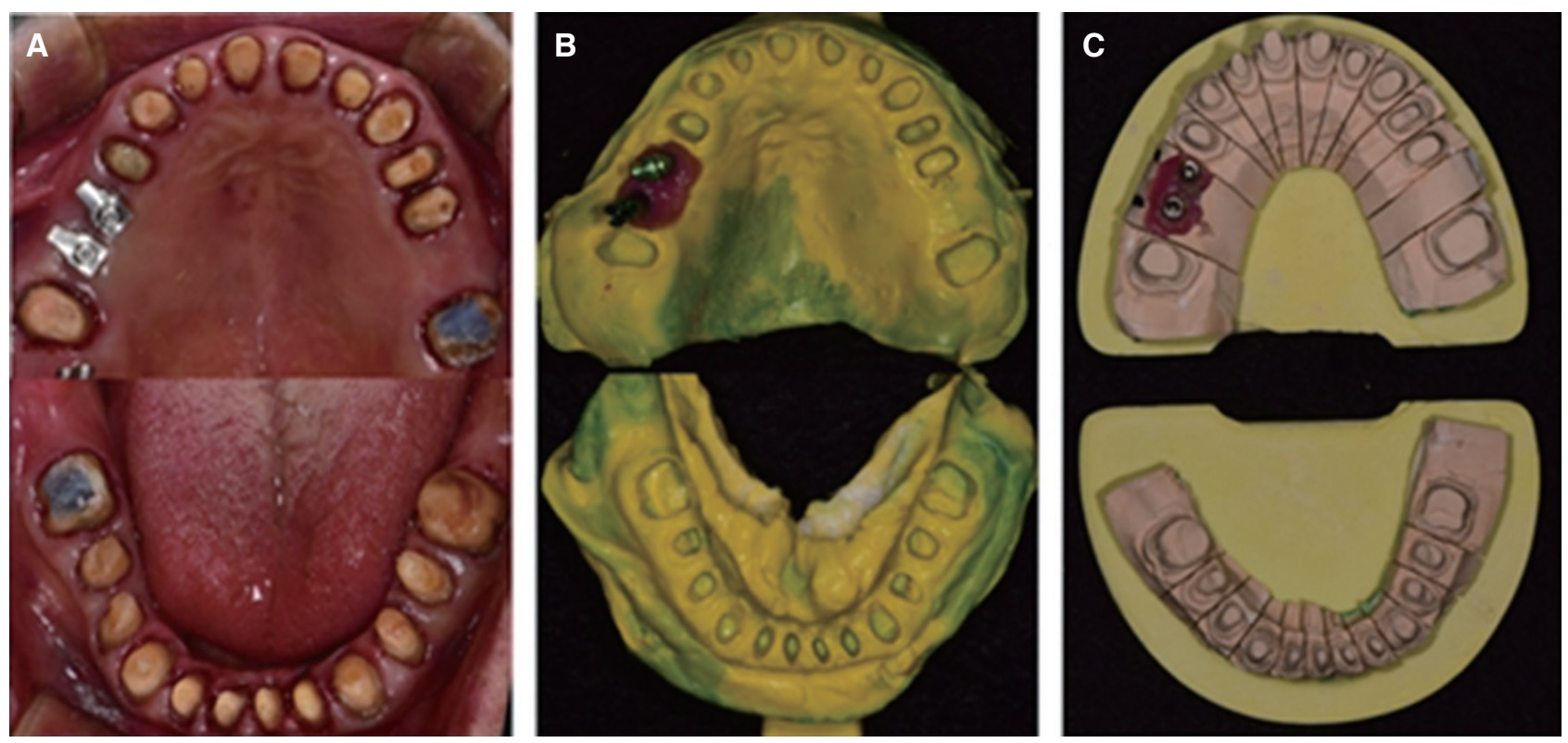

Fig. 5. (A) Tooth preparation, (B) Final impression taking, (C) Die preparation.

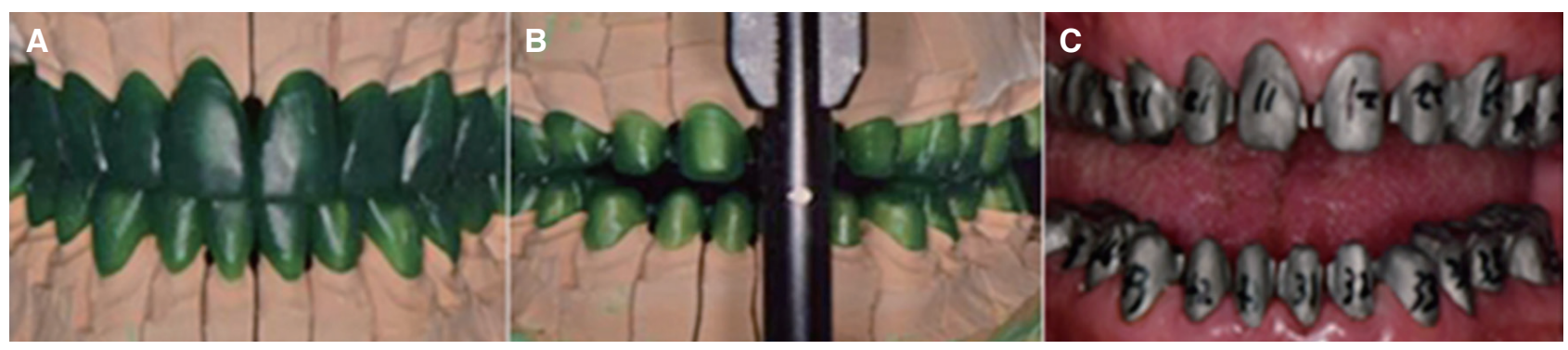

Fig. 6. (A) Full contour wax up, (B) Cut back, (C) Metal coping try in.

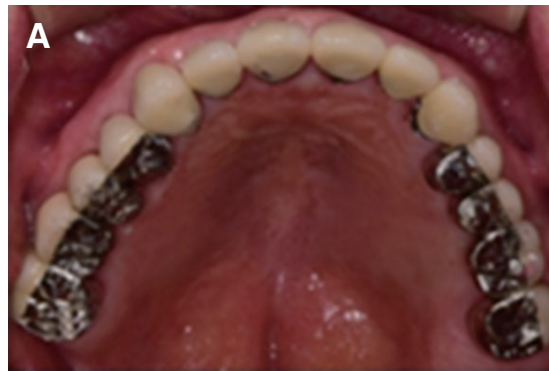

B

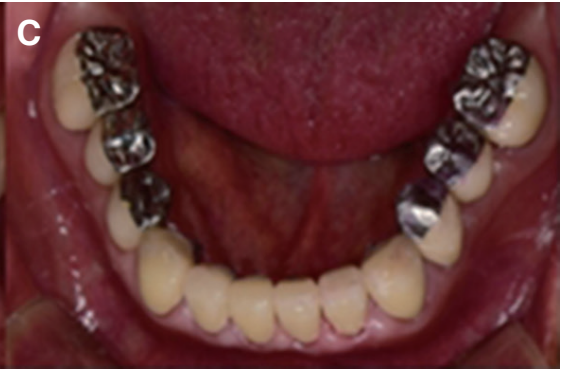

Fig. 7. Definitive prosthesis. (A) Upper view, (B) Frontal view, (C) Lower view.

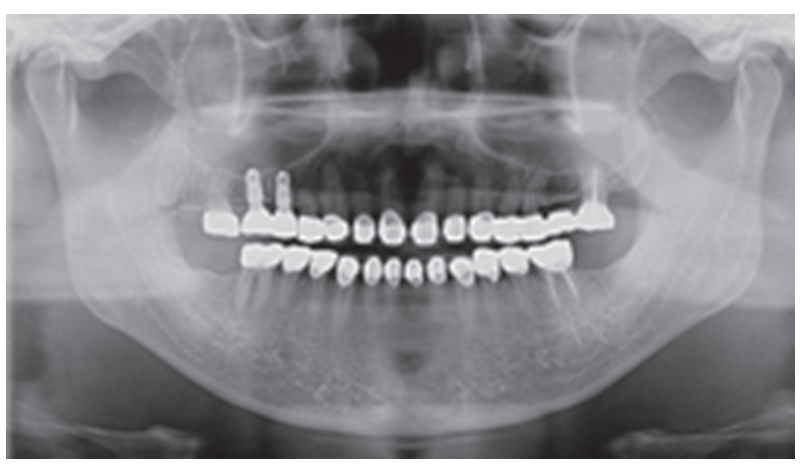

Fig. 8. Panoramic radiograph after treatment.

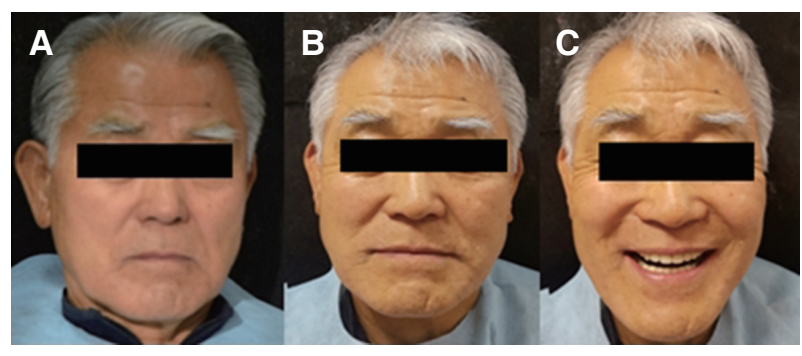

Fig. 9. Extraoral photograph. (A) Before treatment, frontal view, (B) After treatment, frontal view, (C) After treatment, smile. 


\section{고찰}

마모된 치열을 가진 환자의 전악 보철수복에 있어 장 기적으로 성공적인 예후를 얻기 위해서는 마모의 원인을 규명하는 병인론적 평가가 우선되어야 한다. 마모는 교 모, 침식, 선천적 결함, 이갈이 같은 비기능 운동, 구치부 상실에 의한 교합 장애 등이 원인이 되어 발생한다. ${ }^{5}$ 본 증례의 환자도 질기거나 딱딱한 음식을 즐겨 먹는 습관 이 있었고, 이러한 식습관이 마모 및 치아 파절을 가속화 시켰을 것이라 생각된다. 환자에게 질기거나 딱딱한 음 식을 피하고 가능한 부드러운 음식 위주로 식사하도록 교육하였다.

치아마모가 있는 환자에서 교합고경의 거상은 신중하 게 결정되어야 한다. 전악 구강 회복을 할 경우 환자 개개 인에 맞는 수직고경을 설정하는 것은 중요하다. 마모에 의한 수직고경 변화에 대한 논의는 활발히 진행되어 왔 다. Dawson ${ }^{9}$ 은 치아의 마모는 치조골의 성장에 의해 보 상되고 최대 교두 감합위에 부합하는 수직고경을 유지 하여야 한다고 하였고 주장하였다. 무리한 수직고경 거 상은 환자 근육의 정상적인 수축에 문제를 일으켜 근육 통을 유발할 수 있고 악관절 장애까지 일으킬 수 있으 며 결국 치아 함입을 야기할 것이라고 하였다. 이에 반 해 Rivera-Morales와 Mohl ${ }^{10}$ 은 수직고경이 특정한 정적 인 위치가 아닌 범위로 받아들여져야 하며 근신경계의 적 응을 통해 새로운 수직고경을 설정할 수 있다고 하였다. $\mathrm{Abduo}^{11}$ 는 수직고경 거상량은 가능한 적어야 하지만 생 리적 수직고경은 특정한 위치가 아닌 'comfort zone'이라 고 불리는 구간이며 수직고경의 변화가 이 범위안에 한 정될 경우 환자는 새로운 수직고경에 적응하는데 문제가 없을 것이라고 하였다.

본 증례에서는 Willis ${ }^{8}$ 계측법을 통해서 환자의 안모를 평가 하였을 때 동공간선에서 구각부까지의 거리가 콧 날개 아래(alar)에서 하악 하부까지의 거리와 유의할만한 차이가 없었다. Silverman ${ }^{3,4}$ 은 발음이 수직고경 상실을 판단하는 기준이 될 수 있다고 하였는데 본 증례의 환자 는 발음상으로도 특이할 만한 문제점을 가지고 있지 않 았다. 또한 하악 안정위에서 교합면간 거리(interocclusal distance)를 측정하여 정상치와 비교하였고, 상, 하악 전 치의 길이를 평균 거리와 비교하였다. 이에 본 환자는 수 직고경 상실은 없으나 수복을 위한 공간이 부족한 상태 로 진단되어 $3.5 \mathrm{~mm}$ 의 수직고경을 거상함으로써 보철물 제작에 필요한 최소한의 공간을 확보했다. 이후 임시 수
복물 상태로 3 개월 동안 관찰하여 환자의 근신경계 적응 여부를 판단했다. 근육의 피로감, 턱관절 통증, 보철물의 마모 혹은 파절 등이 나타나지 않아, 최종적인 수직고경 거상량을 $3.5 \mathrm{~mm}$ 로 결정하고 최종 보철물을 제작하였 다.

본 증례에서는, 구치부 보철물의 교합면 재료로 금속 을 선택하여 심미적인 부분에 대한 아쉬움이 있었다. 도 재 교합면으로 수복하기 위해서는 수직 고경을 금속 교 합면보다 더 증가시켜야 하고 파절의 우려도 있기에 금 속 교합면으로 제작하였고 비심미적인 부분에 있어서 환 자의 동의를 얻었다.

\section{결론}

본 증례는 과도한 치아 마모가 있는 환자에서 병인을 진단하고 다양한 방법을 통해 - 수직고경을 평가하였으 며 교합 거상량을 결정한 후, 진단 납형을 형성하였다. 임 시 수복물을 장착하고 약 3개월 동안 변화된 수직고경 및 교합양식에 대한 환자의 적응도를 평가한 뒤, 이상 없 음을 확인하고 최종 수복을 시행하였다. 최종보철물 장 착 후, 기능적, 심미적으로 만족할 만한 결과를 얻었고, 장기적으로 좋은 예후를 위해서는 지속적인 경과관찰이 필요하다.

\section{ORCID}

Hwa-Ryun Cha https://orcid.org/0000-0001-9582-2389 Kyeong-Yeon Yeom https://orcid.org/0000-0001-52730492

Yong-Sang Lee https://orcid.org/0000-0002-0707-6177

Na-Hong Kim https://orcid.org/0000-0002-0747-3770

\section{References}

1. Mulay G, Dugal R, Buhranpurwala M. An evaluation of wear of human enamel opposed by ceramics of different surface finishes. J Indian Prosthodont Soc 2015;15:111-8.

2. Ibbetson RJ, Setchell DJ. Treatment of the worn dentition: 2. Dent Update 1989;16:300-2, 305-7.

3. Silverman MM. The speaking method in measuring vertical dimension. 1952. J Prosthet Dent 2001;85:427-31. 
4. Silverman MM. Determination of vertical dimension by phonetics. J Prosthet Dent 1956;6:467-71.

5. Turner KA, Missirlian DM. Restoration of the extremely worn dentition. J Prosthet Dent 1984;52:467-74.

6. Johnson A, Wildgoose DG, Wood DJ, The determination of freeway space using two different methods. J Oral Rehabil 2002;29:1010-3.

7. Park JH, Jeong CM, Jeon YC, Lim JS. A study on the occlusal plane and the vertical dimension in Korean adults with natural dentition. J Korean Acad Prosthodont 2005;43:41-51.

8. Willis FM. Features of the face involved in full denture prosthesis. Dent Cosmos 1935;77:851-4.

9. Dawson PE. Functional occlusion: from TMJ to smile design. St. Louis; Elsevier Health Sciences; 2007. p. 430-52.

10. Rivera-Morales WC, Mohl ND. Relationship of occlusal vertical dimension to the health of the masticatory system. J Prosthet Dent 1991;65:547-53.

11. Abduo J, Lyons K. Clinical considerations for increasing occlusal vertical dimension: a review. Aust Dent J 2012;57:2-10.

12. Oh YR, Lee SB, Park NS, Choi DG. A study of intraoral anatomic landmarks of Korean adult-upper jaw. J Korean Acad Prosthodont 1995;33:753-68. 


\section{심한 치아 마모 환자의 전악보철 수복 증례}

\section{차화륜, 염경연, 이용상, 김나홍*}

한국보훈복지공단 중앙보훈병원 치과보철과

병적 치아 마모의 경우 교합면의 병리적 손상, 기능장애, 교합 이상, 심미문제, 치수병변, 턱관절 장애 등의 증상을 보인 다. 이러한 경우에는 원인을 분석하고 수직고경 손실여부, 교합 양상 등을 고려하여 치료 계획을 세워야 한다. 본 증례는 심한 마모가 있는 71세 남환으로 수직고경 거상을 동반한 전악수복을 하였다. 임시 보철물을 통해 증가된 수직고경에 대 한 환자의 적응도를 평가하였고, 이상 소견이 없는 것을 확인하고 최종 보철물을 장착하였다. 일련의 치료 과정을 통해 만족스러운 결과를 얻었기에 보고하는 바이다.

(구강회복응용과학지 2017;33(3):238-44)

주요어: 치아마모; 수직고경; 전악수복

*교신저자: 김나홍

(05368)서울특별시 강동구 진황도로 61길 53 중앙보훈병원 보철과

Tel: 02-2225-3976 | Fax: 02-2225-3929 | E-mail: tchaski@daum. net

접수일: 2017년 7월 21일 | 수정일: 2017년 8월 16일 | 채택일: 2017년 8월 21일 